\title{
The case for plain packaging
}

\author{
Rob Cunningham, Ken Kyle
}

\begin{abstract}
Plain packaging of tobacco products, also known as generic packaging, is a new tobacco control tool that is being considered by governments in Canada. Plain packaging legislation would require the removal of all attractive aspects of tobacco packaging and would standardise colour, brand name depiction, size, materials, and opening methods. Four empirical studies provide evidence that plain packaging would contribute to a decrease in the use of tobacco products. The many ways in which implementation of plain packaging would benefit tobacco control efforts are discussed, including reasons why consumption would decrease. Responses to the principal arguments put forth by the tobacco lobby against plain packaging are presented.
\end{abstract}

(Tobacco Control 1995; 4: 80-86)

Keywords: packaging, plain (generic); Canada

\section{Introduction}

The plain packaging of tobacco products is currently under intense debate in Canada. In the spring of 1994, the House of Commons Standing Committee on Health held extensive public hearings on the subject. After the hearings, on 21 June 1994, the Committee released a report recommending the implementation of plain packaging providing that a continuing Federal Government study supports available evidence that the measure will reduce smoking. In a news release of 15 September 1994, Canada's provincial Ministers of Health "expressed support of the Federal Minister's commitment to plain packaging, and urged her to proceed with the introduction as quickly as possible."

The hearings produced an unprecedented examination of plain packaging, a new tobacco control measure with tremendous potential. Throughout the process, tobacco industry opposition was exceptionally vigorous. The industry retained lawyers, lobbyists, and various other consultants to help its cause. It also went to great lengths to coordinate new allies in the packaging industry, including companies that print packages, make paperboard, manufacture ink, and engrave printing cylinders.

This article is a condensed version of briefs drafted by the authors for the Canadian Cancer Society and submitted to the Health Committee. Given the relative newness of the plain packaging issue, it was thought that a comprehensive summary of the case for plain packaging, as well as responses to the principal arguments against the measure, would be of value to the international tobacco control community.

\section{What is plain packaging?}

Plain packaging, sometimes referred to as generic packaging or standardised packaging, means removing the attractive, promotional aspects of tobacco product packages. The only distinguishing feature remaining would be the brand name, which would appear in a standardised font, size, colour, and location on the package. Plain packaging would apply to all forms of tobacco products, to carton wrappings, and to tobacco paraphernalia such as cigarette carrying cases and packages of cigarette papers.

Other than the brand name, trademarks and logos would be prohibited. There would be no extraneous writing, markings, or messages on packs. The base colour of the package, other than health warning messages, would be dull and unappealing. Package sizes, materials, and opening methods would be standardised to minimise marketing efforts to differentiate products. As a result, flip tops, tear-top soft packs, oval hinge lid packs, slim packs, "flat $50 \mathrm{~s}$," round cylinders, and packages containing fewer than 20 cigarettes ("kiddie packs") would all be prohibited. Likewise, embossing on the package would not be permitted, with the possible exception of health warning messages, and the texture of the package would be controlled. (A glossy finish, even of an unattractive colour, may render a package more enticing.)

Plain packaging would not prevent the use of computerised bar codes or the inclusion of information required by law, such as the name and address of the manufacturer, a description of package contents (such as " 25 cigarettes"), the listing of toxic constituent levels, and taxpaid markings.

\section{Potential benefits of plain packaging}

There is substantial evidence that plain packaging would contribute to a reduction in tobacco consumption and help change the social context in which smoking is judged. The major arguments in support of plain packaging are summarised below. Packaging regulations could also be used to benefit the environment by ensuring the use of biodegradable paper 


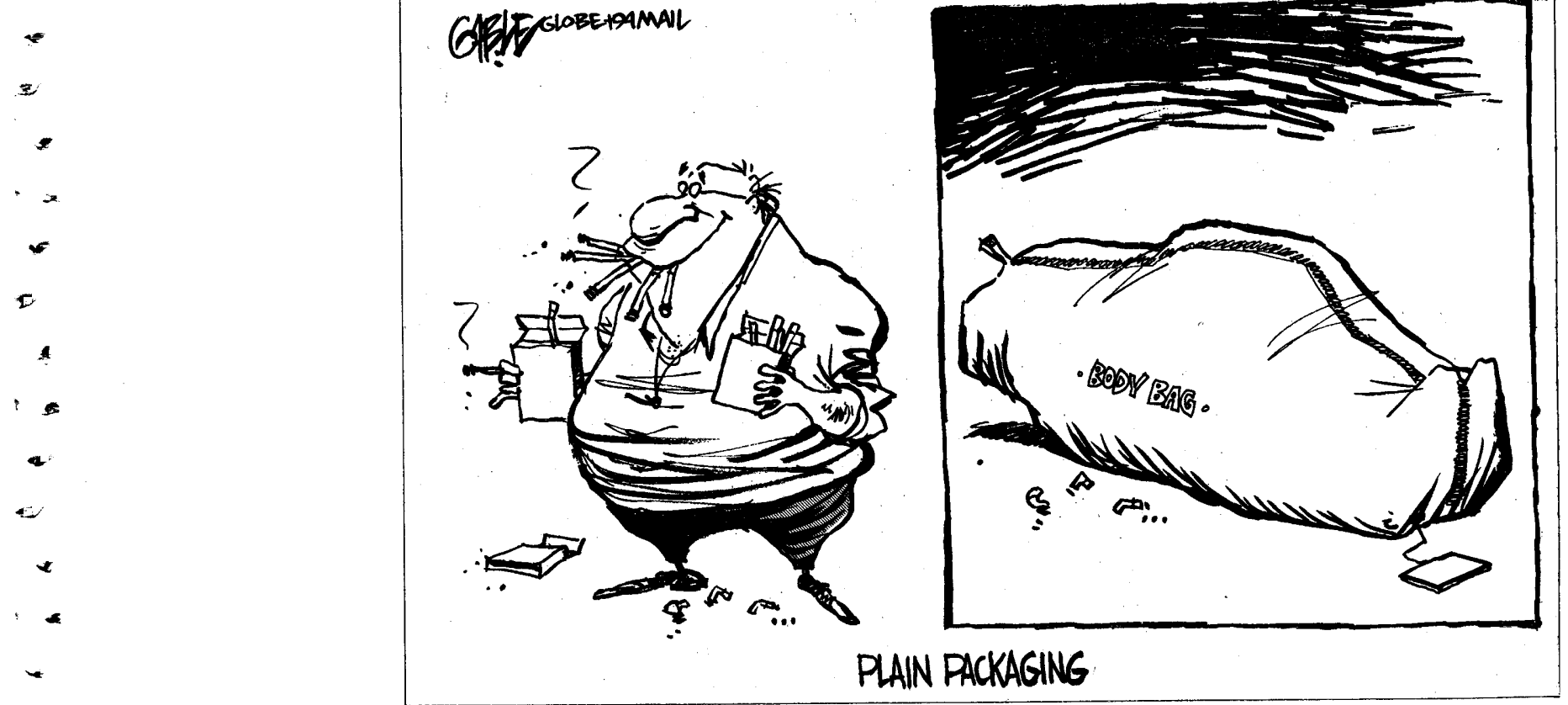

By Brian Gable, reprinted with permission of The Globe and Mail, Canada's national newspaper

products and controlling harmful inks, package finishes and the metallic component of foil wrappings.

\section{REDUCTION OF TOBACCO CONSUMPTION}

There are four empirical studies which provide evidence that plain packaging would likely reduce tobacco use - from the US involving Marlboro smokers, ${ }^{1}$ New Zealand, ${ }^{2-4}$ Australia, ${ }^{5}$ and Canada. ${ }^{6}$ The US study tested the impact of Marlboro brand imagery on smokers. The New Zealand study examined the relationship between the promotional impact of cigarette packaging and adolescent smoking behaviour. The Australian study explored the reactions of adolescents to proposed changes in cigarette packaging. The Canadian study examined whether plain packaging would project less positive images of tobacco products than do brand packages. Three other studies are in progress - two in Canada and one in Australia. Twenty four marketing professors from Canadian universities have also publicly stated their view that it is more likely than not that plain packaging would reduce tobacco use. $^{7}$

Additional evidence that plain packaging would decrease consumption can be found in the experience in both Canada and the US with generic brands. In the US, generic cigarettes have failed to gain a significant market share, indeed the term "generic" cigarettes is often used to refer to lower priced brands, as differentiated from higher priced "premium" brands such as Marlboro and Winston. These generic brands include some brands with fairly plain packaging but also other discounted brands with conventional brand names and packaging (so-called "branded generics"). Many of these discounted brands are advertised, sometimes heavily. Although discounted brands have achieved a sizable market share in the US $\left(30 \%\right.$ in $\left.1992^{8}\right)$, the market share of the truly generic, plain-packaged cigarettes is low. In Canada, no-name unbranded cigarettes sold by chain supermarkets have been a dismal failure, despite lower retail prices. The overall market share for "house" cigarettes is only $0.2 \%$.

The process of smoking initiation itself suggests a valuable role for plain packaging. Children usually obtain their first cigarettes one at a time, before they are brand loyal. The process of initiation involves transformation from experimentation to regular use, a transformation that can take months, or even years. Plain packaging can help interrupt or prolong this process, and in so doing reduce the likelihood that the individual will become a long-term smoker.

ELIMINATION OF PACKAGE AS ADVERTISING Much evidence has been presented in other publications that tobacco advertising increases aggregate demand for tobacco products. ${ }^{9-13}$ The package itself is a form of advertising; as a New Zealand study concluded: "Cigarette packaging functions in the same promotional role as advertising messages". ${ }^{3}$ The growing importance of packaging to the tobacco industry is clear: Tobacco International, an industry trade journal, called the package "an important message carrier" and concluded that "in this struggle to win over smokers, the pack and its message have become increasingly important weapons". ${ }^{14}$ World Tobacco, another industry journal, pointed out that "limitations on advertising will inevitably mean that increasing use will be made of tobacco packs themselves to get brand messages across." 15 This article also included a 


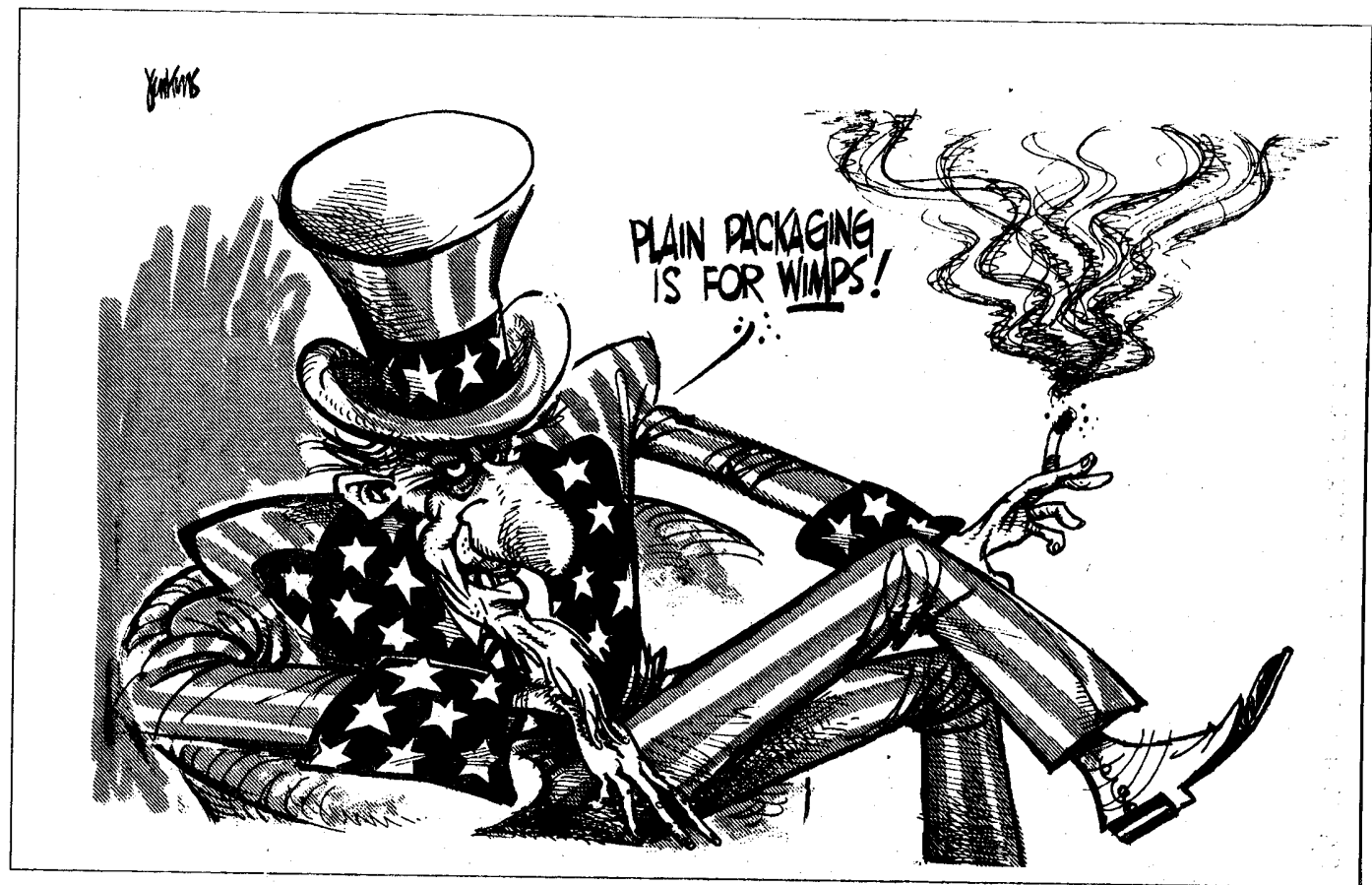

By Anthony fenkins, reprinted with permission of The Globe and Mail, Canada's national newspaper

photograph of a Medallion package and the caption: "WARNING: Cigarette-pack design can be seriously damaged by health warnings, as on this Canadian brand from 1989". Plain packaging would eliminate the package as an important form of advertising.

Tobacco companies create, promote, and sell images such as status, wealth, sex appeal, glamour, sophistication, slimness, manhood, femininity, social acceptability, athleticism, and health. Advertising and packaging mold and propagate those images. A package represents a badge for a smoker, particularly a teenage one. When a pack is taken out of a pocket and opened to remove a cigarette, the pack is visible for all to see. The pack may be passed around for others to have a smoke. Packs make a statement about how smokers want others to see them. Plain packaging eradicates the positive imagery associated with a particular brand, and in so doing, eliminates the role of the cigarette package as a "badge". Instead of being a badge of honour, an ugly pack would discomfort certain smokers. Plain packaging thus would not only diminish positive imagery but also would create negative imagery discouraging smoking.

\section{REDUCTION OF THE IMPACT OF TOBACCO INDUSTRY PROMOTIONAL EFFORTS \\ Advertising}

In addition to eliminating the role of the package itself as a valuable form of advertising, plain packaging would reduce the impact of advertising campaigns, even in countries with an advertising ban. Advertising has a "store of value". ${ }^{10,16}$ Despite the existence of a tobacco advertising ban, past advertising can continue to influence consumers, depending on how long they have been smoking. Tobacco executive Peter Hoult commented, "It's just like the song, you know, The memory lingers on'."17 Plain packaging breaks the link between past advertising campaigns and the continuing advertising presented by the package.

Plain packaging would also serve to diminish the impact of foreign advertising. This is of particular relevance in countries such as Canada that ostensibly have an advertising ban but continue to permit foreign advertising. In Canada, some forms of foreign tobacco advertising remain legal: advertising in foreign magazines distributed within the country; the broadcast of foreign tobacco-sponsored events, such as car racing; and the showing of foreignproduced films containing paid placements of cigarettes. Plain packaging would dramatically decrease the impact of such promotions by breaking the association between the product as advertised from abroad and the product sold at home.

Ironically, one of the arguments used by the Canadian tobacco industry in opposing plain packaging is that foreign manufacturers, through "spillover" advertising in Canada, would have a competitive advantage. This argument is directly contradicted by the written submissions of foreign tobacco companies to the House of Commons. Philip Morris and British-American Tobacco objected to plain packaging on the grounds that it would serve as a market barrier protecting Canadian companies. They argued that plain packaging would prevent penetration of the Canadian market because their brands would no longer have their current distinctiveness.

Sponsorships

Although the sponsorship of sports, arts, and cultural events by tobacco companies was to have been banned in Canada in 1989 under the Tobacco Products Control Act (TPCA), spon- 
sorships of these events, using brand colours, have not only continued but expanded. Plain packaging would diminish the link between sponsorship promotions and the tobacco products being promoted. By eliminating the prime motivation for tobacco companies in sponsoring such events - tobacco product promotion-plain packaging would greatly discourage such activity without necessitating further legislation and without pitting the arts, cultural, and sporting communities against the health lobby.

\section{Shelf displays}

Shelf displays, often positioned at eye level at the checkout counter, are designed to increase the attractiveness of cigarettes and to remind consumers of the opportunity to purchase the product. Faced with this barrage of prosmoking promotion, the motivation not to smoke of an ex-smoker or a smoker trying to quit is inevitably weakened. Self-service counter-top displays also increase minors' access to tobacco, whether by purchase or theft. Unattractive packages are less likely to be prominently displayed; and even if they continue to be, plain packaging curbs the value of shelf displays.

ENHANCEMENT OF PUBLIC EDUCATION EFFORTS Serves as a strong public education vehicle Plain packaging itself is an outstanding form of public education. Plain packaging presents an unparalleled opportunity to change the social acceptability of tobacco use. It sends the message that tobacco is a truly distinct product. By being characterised and treated differently from other consumer goods, tobacco would be singled out as a socially undesirable, lethal product.

Improves effectiveness of other public education tools, including package warnings

Eliminating the pro-smoking messages implicit in the package design and written on the package would reduce the "noise" of the promotional messages against which public education messages have to compete. In Canada, for example, manufacturers have displayed messages such as: "Made with naturally mellowed, premium tobacco for a smooth, full flavour" and "Traditional taste". Calendars have also been included on packages. Plain packaging would outlaw these initiatives. Health promotion efforts would thus be given an environment more conducive to success.

Similarly, plain packaging improves the visibility of health warning messages by removing other messages that compete for the viewer's attention. Research in New Zealand found that recall rates of both health warnings and tar and nicotine content were significantly higher for plain packs than for branded packages. ${ }^{4}$ The greater the impact of health warnings, the more likely a smoker will be receptive to the information and will change behaviour as a consequence. The absence of promotional writing would also enable tobacco packages to carry more detailed health information and a longer list of toxic contents.

\section{INFLUENCE ON CONSUMER PERCEPTION OF} QUALITY AND TASTE

Packaging affects consumer perception of product quality. Even though the product itself may be unchanged, the appearance of the package can affect perceptions of the product inside. Some consumers perceive that "noname" or generic products found in supermarkets are of inferior quality to virtually identical brand name products, when the packaging is basically the only difference.

Research into plain packaging has found that teenage smokers who claimed that they were more interested in the taste and freshness of the product than in the package also said "that the plain package looked 'cheap' and expressed concern that the cigarettes inside might also be cheap, stale or substandard in some other way". ${ }^{6}$ Consumers who perceive cigarettes to be of inferior quality to their previous product, and faced with no viable alternative (branded package), may adjust their behaviour by smoking less.

\section{FEWER PRODUCTS ON THE MARKET}

Plain packaging reduces the ability of manufacturers to differentiate products. According to Canadian tobacco industry lobbyist Rob Parker, "Plain packaging would remove the only device by which the manufacturers can compete among themselves, which is the package design. It becomes a very moot point over what the choice is between one brand and another if the package designs, as a matter of law, are virtually identical."18 The market would not be able to sustain the hundreds of brand variations now available, let alone the various package dimensions in which these variations are available. If they are unable to obtain their preferred product, some smokers may respond by smoking less or quitting altogether.

\section{COSTS GOVERNMENT ALMOST NOTHING TO} IMPLEMENT

Plain packaging would cost the taxpayer virtually nothing - the costs of implementation would be borne by the manufacturer or the consumer, or both. Although manufacturers would incur some one-off costs to convert their packaging, plain packaging would mean continuing reduced expenditures on package design, market research, sponsorships, and other promotions. In Canada, a tobacco industry estimate of $C \$ 30$ million for the conversion works out to about C $\$ 0.015$ per package. Any costs could, of course, be passed on to the customer.

It must be remembered that, although plain packaging presents an opportunity for the tobacco industry to reduce printing costs, governments have a choice. Governments 
could choose not to lower packaging costs by maintaining the complexity of the package design through multicoloured warnings, for example, and thereby protect jobs in the domestic packaging industry.

\section{REDUCTION OF SMUGGLING}

If plain packaging succeeded in helping to control smuggling, it could also increase government revenue. Smuggling undermines the benefits of high tobacco taxes. In jurisdictions that have implemented higher levels of tobacco taxation than their neighbours, plain packaging could make a significant contribution to reducing cigarette smuggling because any package not appearing in the standardised format would be instantly recognisable as illicit. Law enforcement authorities could quickly identify contraband from a distance. Some retailers also sell contraband at normal retail prices to unwitting consumers. Plain packaging would help honest consumers to identify contraband and would give them the opportunity to refuse to accept it.

The tobacco industry argues that plain packaging would actually encourage contraband by making it easier for counterfeiters to reproduce packages. Contrary to their claims, the complexity of the package design could be maintained with plain packaging, as mentioned above. A sophisticated tax-paid marking, such as a hologram similar to those found on credit cards, could further hinder counterfeiting.

The Canadian experience shows, however, that even when tobacco taxes were high, the percentage of the contraband market that was copycat was extremely small. One likely explanation is that tobacco company lawyers would move quickly to shut down any copycat operations; they have not hesitated in the past to stop certain trademark infringements. Because brand names would still appear on plain packages, trademark law gives industry lawyers the authority to initiate action against counterfeiters.

\section{Responses to arguments against plain packaging}

In opposing the implementation of plain packaging in Canada, numerous arguments were advanced by the tobacco industry and others. Below are responses to arguments against plain packaging that were not addressed in detail above.

\section{JOB LOSSES IN PACKAGING AND RELATED INDUSTRIES}

Plain packaging would not necessarily decrease employment in the packaging industry. The complexity of tobacco packaging could be maintained or enhanced. During testimony before a parliamentary committee in Canada, a packaging industry spokesperson said that the use of the rotogravure printing method, a sophisticated process that prevents ink odours from tainting cigarettes, would still be used.

The number of colours on the package could be maintained by increasing the number of colours used in the warning - for example, in addition to the basic brown background and black printing on the package, the warning could be printed on a yellow background or with a yellow or red marker word, such as "Danger". Health-related pictures, such as a pair of lungs, could be used. The inside sliding portion of the package could contain detailed health information. It could also carry a listing of the levels of the dozens of carcinogenic and toxic constituents found in tobacco smoke. A reference to a "QUIT" telephone line could also use colour (the telephone number for a QUIT line is now required on the rear face of cigarette packs in Australia. ${ }^{19}$ )

Under plain packaging, the volume of ink sold by ink companies could increase because most of the package would be covered by a dull, unattractive colour. Currently much of the space on many packs is white without any ink.

Canadian packaging companies suggested to the House of Commons Health Committee that they might move production to the US if plain packaging was required. This threat should be seriously questioned, even if single colour packages were required. Companies would lose experienced workers and would have the expense of retraining, moving major equipment, dealing with customs, and paying tariffs. Transportation costs would also increase as would the risks of foreign currency fluctuations.

Another deterrent to exporting production is that producing plain packages in another country could call attention to the issue in that country. The media and government might object to the fact that a domestic company and workers were producing plain packages for a foreign country but not for its own citizens. They might ask, "Why should public health at home receive inferior treatment to that accorded another country?"

INVENTORY CONTROL AND CUSTOMER SERVICE MADE DIFFICULT FOR RETAILERS

Under plain packaging legislation, crates and boxes containing tobacco products for distribution by wholesalers, and not seen by consumers, could still carry trademarks and brand colours. Boxes stored in a retailer's back room could also feature brand colours and trademarks. The only stipulation would be that these boxes not be exhibited at retail.

Some retailers have also suggested that if all brands looked the same, it would become very difficult to serve customers. This problem could easily be addressed by stacking the brands on shelves in alphabetical order.

TRADEMARKS ARE COMPETITIVE TOOLS BY WHICH MANUFACTURERS COMPETE; PLAIN PACKAGING REPRESENTS CONFISCATION OF TRADEMARKS WITHOUT COMPENSATION

At present, the tobacco industry in Canada operates as an oligopoly and is not price competitive. Regardless of any impact of plain 
packaging on competition, the impact would be subordinate to the public health benefits that would result. Numerous hazardous or undesirable items, from asbestos to cigarette vending machines, have been prohibited or restricted by legislation without compensation.

Tobacco industry trademarks, however, would not be confiscated by government. Governments are not going to start using tobacco trademarks, as would be the case, for example, if tobacco companies were nationalised. Tobacco trademarks would still be available for use. Nothing will prevent any trademark from appearing on boxes/containers used for wholesale distribution. Further, the brand name would still be permitted on consumer packages, albeit in a standardised letter style, colour, and size.

\section{INFRINGEMENT OF INTERNATIONAL TRADE OBLIGATIONS}

Plain packaging would apply equally to all tobacco products, whether domestic or foreign. This principle of "national treatment" is consistent with the General Agreement on Tariffs and Trade (GATT) and other international trade agreements. Furthermore, the current US Administration has stated that it will not challenge the tobacco control laws of foreign countries, even if they infringe international agreements to which the US is a party, as long as they treat domestic and foreign cigarettes in the same fashion. In addition, the GATT and the North American Free Trade Agreement contain health exceptions. The GATT health exception was used in 1990 to uphold Thailand's ban on tobacco advertising.

INFRINGEMENT OF PROTECTION OF FREEDOM OF EXPRESSION

If plain packaging infringes protection of freedom of expression under the Canadian Charter of Rights and Freedoms, it would nevertheless be a reasonable and justifiable limit on that freedom given the enormous burden on public health caused by tobacco products. Commercial expression, such as trademarks, is hardly at the core of the historic and fundamental right of freedom of expression. In a number of countries such as Canada, commercial expression has been recognised by the courts as deserving less protection than political, religious, or artistic expression.

\section{A DANGEROUS PRECEDENT: TOBACCO TODAY, WHAT NEXT?}

Tobacco is a unique consumer product. If it were a new product today, it would not be allowed on the market. Tobacco is toxic, carcinogenic, and addictive. No other consumer product legally available on the market kills when used exactly as the manufacturer intends, and there is no safe level of consumption. For these reasons, tobacco merits legislative and regulatory treatment different from all other products.

The argument that implementing such a restrictive measure for tobacco will inevitably lead to further draconian measures by government was used during the debate in 1988 over the proposed ban on tobacco advertising in Canada. At the time, opponents argued that, if tobacco advertising was banned, the precedent would lead to advertising bans for other goods and services. This has not happened.

\section{IF PRICES DECREASE, CONSUMPTION WOULD} INCREASE

If manufacturers did decrease their prices, governments would step in and raise tobacco taxes by a corresponding amount. The constant retail price would ensure that there is no increase in consumption.

\section{CONSUMPTION WOULD INCREASE AMONG THE} YOUNG

Some opponents of plain packaging have argued that it might increase smoking among the young, being an even more effective badge of teenage rebelliousness than an attractive, branded package. For this argument to be true, however, the corollary - that attractive packages discourage consumption-would also have to be true. The latter is a proposition with which few industry executives would agree. Given the millions of dollars tobacco companies spend on package design and market research, if there were such a tobacco product or package that would increase sales within a particular population segment, while reducing packaging costs, the tobacco industry would have introduced it themselves.

The argument has also been made that the popularity of "Death" brand cigarettes among youth in the UK and elsewhere proves that plain packs would not result in a decrease in youth smoking. "Death" cigarettes, however, are a novelty item and are in no way plain packs. As in the case of conventional brands, its packaging plays a major role in defining the brand's image and in making the brand attractive to its users. Moreover, the company that makes them is forecasting only a minuscule 1994 market share of $0.06 \%{ }^{20}$

\section{SMOKERS COULD PUT CIGARETTES IN OTHER}

\section{FORMS OF PACKAGING}

Most smokers, like other consumers, value convenience. Only a small proportion would likely transfer their cigarettes into cigarette cases. Even if all smokers did so, plain packaging would still have accomplished significant results. Plain packaging would continue to reduce the impact of sponsorships, shelf displays, and foreign advertising, while sending an important public education message.

PACKAGING NEVER MADE ANYONE BUY SOMETHING THEY DID NOT WANT

This argument has no meaning. A price discount never makes anyone buy something they did not want either. A $\$ 10000$ reduction 
in the price of a new car, for example, would not make a purchaser buy a car if the purchaser did not want one. But a price discount can certainly influence the individual's level of desire for the object. The same is true for packaging. Packaging contributes to the image conveyed by a cigarette brand, and thereby serves to heighten the individual's desire to have the product.

\section{SALES IN RAW LEAF TOBACCO, WITH NO PACKAGING, HAVE INCREASED}

Sales of raw leaf tobacco in Canada have grown because its lower tax rate makes the retail price favourable compared with manufactured cigarettes. The market share for consumer sales of raw leaf tobacco remains small.

\section{IT HAS NOT STOPPED SALES OF MARIJUANA AND OTHER DRUGS}

The rate of consumption of marijuana and other drugs is significantly lower than that of tobacco. If marijuana were legalised, sold in attractive packages, prominently displayed in countless retail stores, and actively promoted, it is reasonable to expect that the rate of marijuana use would increase.

\section{LEGISLATION SHOULD BE DELAYED UNTIL THE IMPACT OF THE NEW CANADIAN HEALTH WARNINGS IS MEASURED}

With every delay, more young people will begin smoking and more smokers, who might otherwise have been influenced to quit, will remain in the market. This will translate into additional preventable deaths caused by tobacco in the future. The Canadian tobacco industry vigorously opposed the new health warnings, arguing that there was no proof that stronger warnings would be any more effective than the old ones. The industry now says that plain packaging should wait until an evaluation is made of the new warnings. This is plainly an industry stalling tactic.

\section{Conclusions}

The weight of evidence on numerous fronts clearly indicates that plain packaging can be expected to result in a decrease in tobacco consumption. The package is a form of advertising, an increasingly important form in jurisdictions, such as Canada, where media advertising has been banned but tobacco company sponsorships continue. Plain packaging would eliminate the positive imagery associated with the brand and would break the link between the package and the sponsorship promotions. Plain packaging would also enhance public education efforts and itself would send the message that tobacco is a unique consumer product, meriting distinct legislative and regulatory control. Although the tobacco industry has opposed the implementation of plain packaging - citing everything from job losses in the packaging and printing industries, to an infringement of trade laws, to a resultant increase in cross-border smuggling - convincing counter-arguments have been presented. Plain packaging represents an as yet untried tobacco control tool with tremendous potential. The authors gratefully acknowledge the editorial assistance of
Melodie Tilson.

1 Trachtenberg JA. Here's one tough cowboy. Forbes 1987 Feb 8: 108-10

2 Beede P, Lawson R. The effect of plain packages on the perception of cigarette health warnings. Public Health 1992; 106: 315-22.

3 Beede P, Lawson R. Brand image attraction: the promotional impact of cigarette packaging. NZ Fam Phys $1991 ; 18: 175-7$.

4 Beede $P$, Lawson $R$, Shepherd $M$. The promotional impact of cigarette packaging: a study of adolescent responses to cigarette plain-packs. Paper presented to the Australian and New Zealand Association and Management Educators' Conference, Launceston, Australia, 1991.

5 Adolescents' reactions to cigarette packs modified to increase extent and impact of health warnings. In: Health warnings and contents labelling on tobacco products. Melbourne, Australia: Anti Cancer Council of Victoria, 1992.

6 University of Toronto Centre for Health Promotion. Effects of plain packaging among youth. Toronto, Ontario: University of Toronto Centre for Health Promotion, 30 November 1993.

7 Marketing professors endorse plain packaging of tobacco products (press release). Ottawa, Ontario: Canadian products (press release). Ottaw
Cancer Society, 1994 May 23.

8 Shapiro E. Trend toward quitting smoking slows as discount cigarettes gain popularity. Wall Street $\mathcal{F} 1993$ April 1: B1, B8.

9 Foote E. Advertising and tobacco. $\mathcal{f} A M A 1981 ; 245$; $1667-8$

10 Pollay RW. The functions and management of cigarette advertising. History of advertising archives, Working paper, Faculty of Commerce, University of British Columbia, 1989

11 Tye JB, Warner KE, Glantz SA. Tobacco advertising and consumption: evidence of a causal relationship. $\mathcal{F}$ Public Health Policy 1987; 8: 492-508.

12 UK Department of Health. Effect of tobacco advertising on tobacco consumption : a discussion document reviewing the evidence. London: Department of Health, Economics and Opidence. London: Department of Health,

13 US Department of Health and Human Services. Preventing tobacco use among young people. A report of the Surgeon General. Atlanta, Georgia: Public Health Service, Centers for Disease Control and Prevention, Office on Smoking and Health, 1994 (US Government Printing Office No S/N 017-001-00491-0.) 14 Staff Report. Rethinking cigarette packs for a new age.
Tobacco Int 1991 Mar 1 : 14 .

15 Joy R. Regulations create design limitations. World Tobacco 1992 May: 17

16 Carr-Gregg M, Gray AJ. 'Generic' packaging - a possible solution to the marketing of tobacco to young people. Med F A ust 1990; 153: 685-6.

17 RFR-Macdonald v. Attorney General of Canada, transcript, 1989 Sep 27: 402 .

18 Rob Parker, President, Canadian Tobacco Manufacturers' Council, appearing before the Ontario Standing Committee on Social Development. Hansard 1994 Feb 17: S1202.

19 Chapman S. Industry down again down under. Tobacco Control 1995; 4: 17-18.

20 A product to die for. CTN 1994 Feb 25: 11. 